Article

\title{
The Game Simulation of "The Belt and Road" Economic and Trade Network Based on the Asymmetric QRE Model
}

\author{
Changping Zhao ${ }^{1}$, Yecheng Wang ${ }^{1}$, Tianxiang Zhang ${ }^{2}$, Qingbo Huang ${ }^{1, *}$ and Yu Gong ${ }^{3}$ (I) \\ 1 School of Maritime Economics and Management, Dalian Maritime University, Dalian 116026, China; \\ zhao0037@sina.com (C.Z.); wangyecheng7@163.com (Y.W.) \\ 2 School of Business, Anhui University of Technology, Ma'anshan 243032, China; txzh87@ahut.edu.cn \\ 3 Southampton Business School, University of Southampton, Southampton SO17 1BJ, UK; y.gong@soton.ac.uk \\ * Correspondence: huangqingbo@dlmu.edu.cn; Tel.: +86-(0)-411-84726698
}

Received: 16 May 2019; Accepted: 17 June 2019; Published: 18 June 2019

\begin{abstract}
This paper introduces the asymmetric Quantal Response Equilibria (QRE) network game model to explain the influencing factors on the cooperative behavior of "The Belt and Road" countries. The findings suggest that the belief in the sensitivity to own payoff and counterparts, the reward for cooperation by neighbor nodes, the trade facilitation index, and the reduction rate of tariffs were incorporated to have a significant impact on the Belt and Road cooperation. Our findings provide important policy references to the belt and road countries.
\end{abstract}

Keywords: "The Belt and Road"; economic and trade network; asymmetric QRE model; game simulation

\section{Introduction}

Over the past five years or so, China has engaged in extensive communication and coordination with participating countries and international organizations, and reached a broad consensus on international cooperation for building "The Belt and Road" (B\&R). While committed to respecting the sovereignty and security concerns of all relevant countries, $B \& R$ countries have made concerted efforts to build an all-round, multi-level, and composite infrastructure framework centered on railways, roads, shipping, aviation, pipelines, and integrated space information networks. This framework is taking shape rapidly. It has greatly reduced the transaction costs of products, capital, information, and technologies flowing between regions, and effectively promoted the orderly flow and optimal allocation of resources among different regions. The efforts invested in the initiative have liberalized and facilitated trade and investment in the participating countries and regions, lowered the costs of trade and business, and releasing growth potential, enabling the participants to engage in broader and deeper economic globalization. Exploring investment and financing models, international multilateral financial institutions and commercial banks have played an innovative role in expanding the channels of diversified financing, providing stable, transparent, and quality financial support for the Belt and Road Initiative. The B\&R countries have carried out diplomatic activities and cultural exchanges of various forms in wide fields, enhancing mutual understanding and recognition and laying a solid cultural foundation for furthering the initiative [1].

These achievements show that "The Belt and Road" is an important cooperation platform to jointly build, share mutually beneficial cooperation, and link up each country's development strategy. "The Belt and Road" has become the hottest topic of global politics and economy. Its development process directly affects the nerves of global public opinion and the community of shared future for 
mankind, and cooperation is the core mechanism to build it. However, how to cooperate and take measures to promote cooperation has become an urgent issue for all countries.

Since 2013, when President Xi Jinping attended the meetings in Kazakhstan and Indonesia and proposed a new concept for the economic belt of the Silk Road and the Silk Road on the sea, domestic and foreign scholars have widely interpreted the concept as "The Belt and Road". There are foreign scholars who interpret it as China's "Marshall Plan" [2], which is regarded as a game strategy against the United States [3]. Another view is that "The Belt and Road" can promote regional economic integration [4], promote the integration of Asian regions and the World and promote maritime connectivity [5]. It is a diplomatic philosophical strategy of mutual benefit and security. Chinese scholars argued that "The Belt and Road" strategy provides a connecting hub for the political body of geo-space [6], which can inject vitality into global governance and help reduce the geographical competition between China and the United States [7]. From the content of the study, the results have been concentrated on the mutually beneficial cooperation in economy and trade [8], the regional industrial upgrading [9], the discussion on the global model of sustainable regional development [10], the development of regional economic integration [11], the Chinese companies outbound strategy [12], RMB internationalization [13], the importance of infrastructure construction [14], exploration of intentional consumption behavior of green products [15], and Sino-Indian co-operative relations [16].

Regarding the research methods, qualitative analysis, trade gravity model, panel data analysis [17], econometric methods, and exponential random graph model (ERGM) [18] have been applied as the main methods. However, it is noteworthy that, as a method of analyzing the behavior between different subjects, the related research on "The Belt and Road" in the complex network is still lacking. Fu et al. [19] constructed a Belt and Road trade cooperation network from a multi-distances perspective under the backdrop of the Belt and Road initiative based on the cooperation network formation theory. They selected geographic, factor endowment, cultural, and institutional distances as variables from aspects of geography, economy, culture, and politics to expand the gravity model. With that model, an empirical test was conducted using the data from China's export trade flows to Belt and Road countries from 2007 to 2016. Different from previous empirical studies, our research further introduces the game model on the basis of complex networks, and explores the cooperation behavior between the countries along "The Belt and Road" on the complex network through simulation of various factors in the game process.

In 1995, the Quantal Response Equilibria (QRE) model was first used in game experiment by Mckelvely and Palfrey [20]. Friston et al. [21] considered goal-directed decision-making in terms of embodied or active inference associated with softmax functions and quantal response equilibria. Lim and Ho [22] explained the results of experiments of the number of blocks in price contracts for bounded rational customers by a QRE model. Ho and Zhang [23] embedded utility function in a QRE framework to study the framing of the fixed fee. Guarnaschelli, McKelvey and Palfrey [24] explained the experimental results on groups facing a decision problem analogous to that faced by a jury using QRE. Levine and Palfrey [25] tested the voter turnout predictions of the rational choice Palfrey-Rosenthal model of participation with asymmetric information by comparing the deviations from the Nash equilibrium and the logit version of QRE. Choi, Gale, and Kariv [26] explored the relationship between equilibrium behavior in a class of monotone games and the behavior of human subjects in an experimental setting with an estimated model of QRE. Tumennasan [27] studied the implementation problem when players are prone to make mistakes with the Logit Quantal Response Equilibrium (LQRE). Golman [28] introduced a model of QRE with heterogeneous agents and demonstrated the existence of a representative agent for such populations. In addition, by incorporating the endogenous factors affecting human decision-making into the equilibrium analysis, a balanced paradigm which is not based on complete rationality was developed by modifying the behavior of participants $[29,30]$.

Based on the theoretical foundation of the above QRE model, we introduce the asymmetric QRE model into the "The Belt and Road" economic and trade network to explore the situation 
of the cooperative game. This paper attempts to simulate the cooperative game by introducing the asymmetric QRE model based on the construction of "The Belt and Road" economic and trade network [31,32]. When different variables have different degrees of influence on the entire system [33,34], the simulation process mainly changes the factors such as the belief in the sensitivity to own payoff and counterparts [21], the reward for cooperation by neighbor nodes [35], the trade facilitation index [36], and the reduction rate of tariffs [37]. Based on the outcomes, we then analyze the influence of the various factors on the cooperation of "The Belt and Road" economic and the trade network.

The rest of this paper is organized as follows: The construction of "The Belt and Road" economic and trade network is provided in Section 2. The network game with asymmetric QRE model is given in Section 3. The simulation experiments and evaluation results are provided in Section 4. Finally, conclusions and future work are discussed in Section 5.

\section{Methodology}

\section{1. "The Belt and Road" Complex Network}

The main object of the research model was the 65 countries along "The Belt and Road". According to their geographical locations, we divided the countries into different regions as shown in Table 1:

Table 1. Countries list of "The Belt and Road".

\begin{tabular}{cc}
\hline Regions and Organizations & Countries \\
\hline West Asia (17) & $\begin{array}{c}\text { Bahrain, Cyprus, Greece, Iran (Islamic Republic of), } \\
\text { Iraq, Israel, Jordan, Kuwait, Lebanon, Oman, Qatar, } \\
\text { Saudi Arabia, State of Palestine, Syrian Arab } \\
\text { Republic, Turkey, United Arab Emirates, Yemen }\end{array}$ \\
\hline South Asia (8) & $\begin{array}{c}\text { Afghanistan, Bangladesh, Bhutan, India, Maldives, } \\
\text { Nepal, Pakistan, Sri Lanka, }\end{array}$ \\
\hline Central Asia (5) & $\begin{array}{c}\text { Kazakhstan, Kyrgyzstan, Tajikistan, Turkmenistan, } \\
\text { Uzbekistan }\end{array}$ \\
& $\begin{array}{c}\text { Albania, Armenia, Azerbaijan, Belarus, Bosnia and } \\
\text { Herzegovina, Bulgaria, Croatia, Czechia, Estonia, } \\
\text { Georgia, Hungary, Latvia, Lithuania, Macedonia, } \\
\text { Montenegro, Poland, Republic of Moldova, Romania, } \\
\text { Serbia, Slovakia, Slovenia, TFYR of Russian } \\
\text { Federation, Ukraine }\end{array}$ \\
\hline East Asia (12) & $\begin{array}{c}\text { Brunei Darussalam, Cambodia, China, Indonesia, Lao } \\
\text { People's Dem. Rep., Malaysia, Mongolia, Myanmar, } \\
\text { Philippines, Singapore, Thailand, Vietnam }\end{array}$ \\
\hline
\end{tabular}

Source: Sorted by the author (according to the coverage area of "Promote the construction of the Silk Road Economic Belt and the vision and action of the maritime Silk Road in 21st century" [38]).

Taking the countries shown in Table 1 as the nodes of the network, various economic and trade cooperation exists between the countries, the data on trade in goods reflect the state of trade cooperation among these countries, we obtained the bilateral trade data from 2008 to 2017 of these countries from UNCTDs [39]. There are a lot of developing countries along the "The Belt and Road", and there are political conflicts in some countries, while the bilateral trade between some countries is very small. Thus, in order to fully reflect the characteristics of the trade network of "The Belt and Road" countries and to avoid generating too many independent nodes, we took the value of the average bilateral trade volume for the decade 2008-2017 along "The Belt and Road" as the basis for judgment. Therefore, 10 million U.S. dollars was taken as the benchmark. If it was exceeded, it was determined that there was a trade relationship between the two countries. The corresponding value of its adjacency matrix was assigned a value of 1 , otherwise, assigned 0 . 
We applied UCINET software to draw up the "The Belt and Road" economic and trade network, the results as shown in Figure 1:

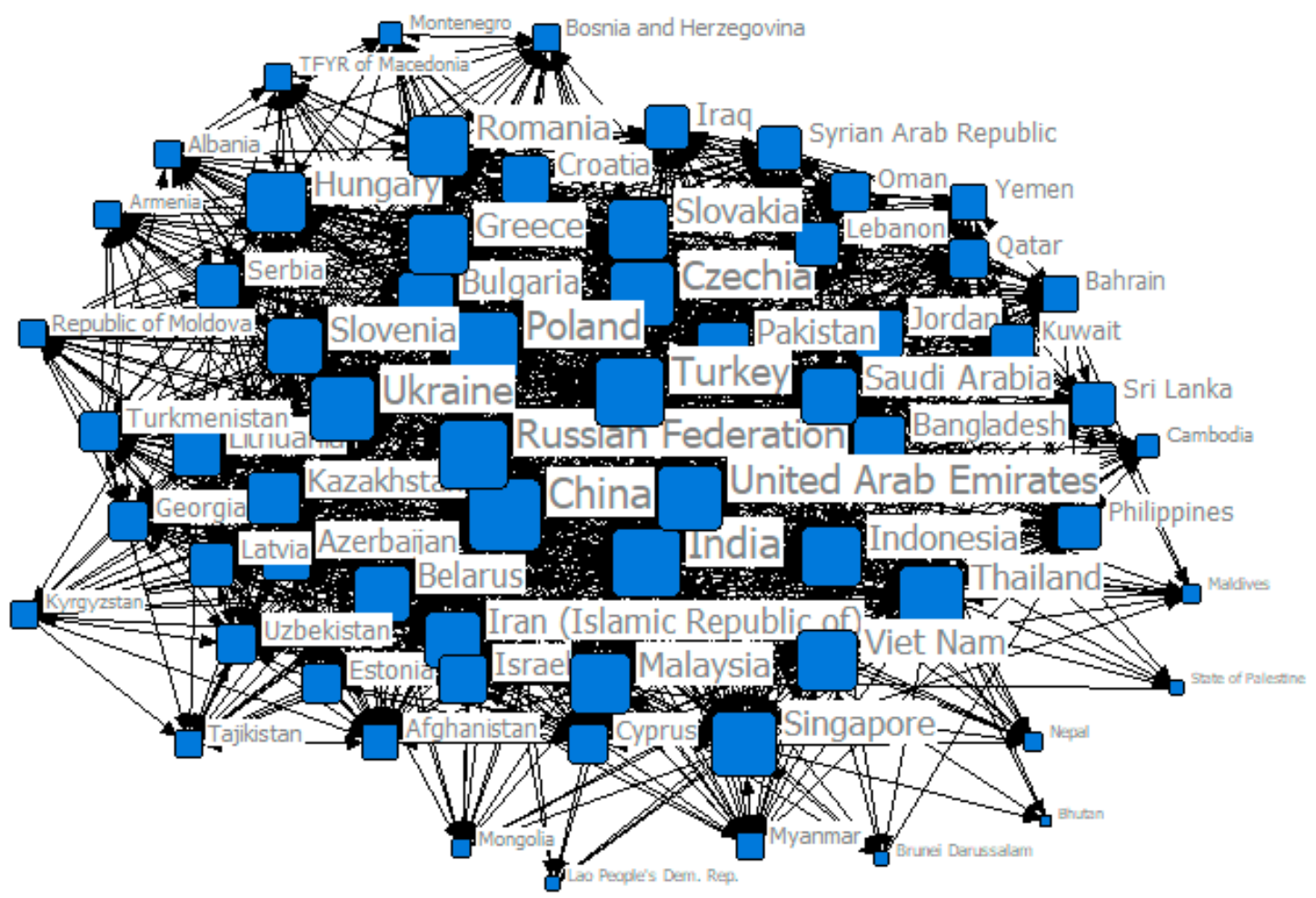

Figure 1. "The Belt and Road" trade network.

Transforming the "Belt and Road" complex network into a $65 \times 65$ relational matrix. In this matrix, if there is a trade volume between countries that exceeds the set trade volume, there is a closer economic and trade relationship between the two countries with a network connection between the nodes. The total number of 1 in a row in the matrix is the number of neighbors for that line's representative country. The degree of the node country measures the number of neighbors of the node country, so it means the degree of the node is the total number of neighbors, which was set as $N_{i}$.

We calculated the degree of the nodes $\mathrm{K}=[6,9,9,31,27,33,44,2,18,8,46,14,63,33,17,54,26,19$, $46,50,61,46,42,20,36,27,36,27,10,4,30,19,35,50,2,2,8,17,4,27,41,27,57,28,17,50,57,42,31,54$, $47,47,30,3,19,10,53,18,59,23,55,50,26,47,15]$.

\subsection{Asymmetrical QRE Model}

The participants' thinking steps and their beliefs in other participants' sensitivity affect their expected payoff and strategy choice [40]. QRE further expands the concept of equilibrium on the basis of Nash equilibrium [41-43]. The theory holds that participants pursue rationality in their beliefs, but inevitably make mistakes in calculating the expected utility of each strategy, which is determined by human's innate limited cognitive ability [20]. Therefore, in practice, the optimal choice under Nash equilibrium does not appear as probability 1, which means complete rationality. QRE is often expressed through logit model or exponential payoff reaction function:

$$
P\left(s_{i}\right)=\frac{\exp \left[\lambda_{i} \sum_{s_{-i}} P\left(s_{-i}\right) U_{i}\left(s_{i}, s_{-i}\right)\right]}{\sum_{s_{k}} \exp \left[\lambda_{i} \sum_{s_{-i}} P\left(s_{-i}\right) U_{i}\left(s_{k}, s_{-i}\right)\right]},
$$

$P\left(s_{i}\right)$ indicates the probability of $\mathrm{i}$, one of the game participants, adopting $s_{i}$ strategy. Numerator indicates that when the probability of the other game participant adopting $s_{-i}$ strategy is $P\left(s_{-i}\right)$, the expected return of $i$ adopting $s_{i}$ strategy is $\sum_{s_{-i}} P\left(s_{-i}\right) U_{i}\left(s_{i}, s_{-i}\right)$; Denominator indicates the total 
expected return of $\mathrm{i}$ when taking $\mathrm{k}$ strategies. The sign $\mathrm{k}$ is the number of all possible strategies that are available for $\mathrm{i}$, and $s_{i} \in s_{k}$.

QRE incorporates the endogenous factors in human decision-making into equilibrium analysis, and develops a balanced paradigm that is not based on complete rationality by modifying the behavior of participants [44]. This makes the equilibrium analysis of economics move one step further. The asymmetric QRE model can be obtained by incorporating the asymmetric cognition that participants always think they are smarter than others into the analysis of the game equilibrium. The logit form of asymmetrical QRE is defined as follows:

$$
\begin{aligned}
P\left(s_{-i}\right) & =\frac{\exp \left[\widetilde{\lambda_{-i}} \sum_{s_{i}} P\left(s_{-i}\right) U_{-i}\left(s_{i}, s_{-i}\right)\right]}{\left.\sum_{s_{-k}} \exp \left[\widetilde{\lambda_{-i}} \sum_{s_{i}} \widetilde{P\left(s_{i}\right.}\right) U_{i}\left(s_{i}, s_{-k}\right)\right]}, \\
P\left(s_{i}\right) & =\frac{\exp \left[\lambda_{i} \sum_{s_{-i}} \widetilde{P}\left(s_{-i}\right) U_{i}\left(s_{i}, s_{-i}\right)\right]}{\sum_{s_{k}} \exp \left[\lambda_{i} \sum_{s_{-i}} \widetilde{P}\left(s_{-i}\right) U_{i}\left(s_{k}, s_{-i}\right)\right]},
\end{aligned}
$$

$P\left(s_{i}\right)$ and $\widetilde{P}\left(s_{-i}\right)$ indicate the probability of game participants, $i$ and $-i$, adopting $s_{i}$ and $s_{-i}$ strategy respectively. $\lambda_{i}$ and $\lambda_{-i}$ express the belief in the sensitivity of own payoff and the sensitivity of their counterparts respectively.

In the asymmetric QRE model, the probability of $\mathrm{i}$, one of the participants, adopting $s_{i}$ strategy is related to self-sensitivity cognition and expected utility of the other participants. The expected probability of other participants adopting $s_{-i}$ strategy is related to participants' beliefs in the sensitivity of their reactions and the expected utility of other participants. $P\left(s_{i}\right)$ and $\widetilde{P}\left(s_{-i}\right)$ form a loop nesting relationship. This model can better explain that when the participants' perception of their own sensitivity is inconsistent with that of their counterparts' reaction sensitivity, the equilibrium of the game is not the optimal solution, and the phenomenon of sub-optimal selection may occur. The asymmetric QRE model was introduced into the game model of the economic and trade network of "The Belt and Road", which can better explain the sensitivity to payoff and the effect of the difference of decision steps on the equilibrium results. The endogenous factors of participating countries were incorporated into the analysis of the network game so that the conclusion would have a stronger explanatory power.

\section{The Network Game Model}

\subsection{Model Assumptions}

In "The Belt and Road" economic and trade network in Figure 1, the nodes represent countries and regions, and the edges in the network represent the game relationship among the network participants. Each country is a rational economic man, pursuing profit maximization. Whether or not these countries participate in "The Belt and Road" economic and trade network depends on whether the maximum benefits can be obtained from their participation. Based on the actual situation of "The Belt and Road" economic and trade network, the following assumptions were made for the model of the network game.

Hypothesis 1: Assuming that each node country is homogeneous, the impact of economic and trade cooperation on each country is consistent and brings the same benefits to each country. The purpose of our study was to test the influence of factors on the trend of cooperative game, so this hypothesis would not substantially change the research results.

Hypothesis 2: In a social dilemma, the income relationship generated by strategy combination must satisfy the following four conditions:

a. $\quad$ R $>$ P. Game players prefer to cooperate together rather than betray each other. 
b. $\quad$ R $>$ S. Game players prefer to cooperate together rather than unilaterally.

c. $2 R>T+S$, the benefits of joint cooperation are greater than the collective benefits of unilateral cooperation or unilateral betrayal.

d. $\quad \mathrm{T}>\mathrm{R}$ or $\mathrm{P}>\mathrm{S}$, the players prefer to betray unilaterally rather than cooperate together or the players prefer to betray jointly rather than cooperate unilaterally.

$s_{i}=\{0,1\}$ represents the strategy set of node $i$. There are two strategies for node $i$ that are optional in the game, 1 for cooperation and 0 for betrayal. Therefore, the income payoff matrix can be obtained as shown in Table 2:

Table 2. Single game payoff matrix.

\begin{tabular}{lccc}
\hline \multirow{2}{*}{ Single Game of Node $\mathrm{i}, \mathrm{j}$} & \multicolumn{2}{c}{ Strategy of Node $\mathrm{j}$} \\
\cline { 3 - 4 } & & Cooperation & Betrayal \\
\hline \multirow{2}{*}{ Strategy of Node $\mathrm{i}$} & Cooperation & $\mathrm{R} ; \mathrm{R}$ & $\mathrm{S} ; \mathrm{T}$ \\
& Betrayal & $\mathrm{T} ; \mathrm{S}$ & $\mathrm{P} ; \mathrm{P}$ \\
\hline
\end{tabular}

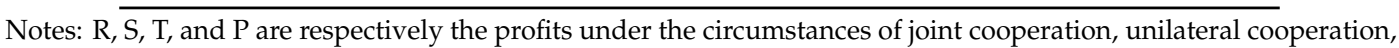
unilateral betrayal, and common betrayal.

Hypothesis 3: Participants choose cooperation and non-cooperation strategies according to probability, assuming that they cooperate according to probability $P\left(s_{i}\right)$ and choose non-cooperation according to probability $1-P\left(s_{i}\right)$.

Hypothesis 4: Each node country is affected by its neighbor nodes. The neighboring nodes have close trade relations with them, and they can affect the game gain of the node through reward and penalty. Suppose the reward of the cooperative action given by each neighbor node is $w_{i j}$, and the total reward that node i gets from its neighbors is $\sum_{j \in N B R} w_{i j}$.

Hypothesis 5: Assuming the trade facilitation index is $f$, which means the degree of trade facilitation promotes economic growth, the amount of economic growth brought about by trade facilitation is $f^{*} Y(i)$, and $Y(i)$ is the average value of the GDP in 2008-2017 of the node country $i$.

Hypothesis 6: Assuming that the economic and trade network community gives member countries a tariff rate reduction rate of $r, r \in[0,1]$, then the tax concession obtained by a member state joining the community is $r$ multiplied by its total trade. $Q(i, j)$ is the average value of trade volume in 2008-2017 between node $i$ and node $j$.

Table 3 provides the detailed descriptions of the above variables.

Table 3. Description of variables.

\begin{tabular}{ccc}
\hline Variable & Description & Range \\
\hline$\lambda_{i}$ & The belief in the sensitivity to own payoff & {$[0,+\infty)$} \\
$\lambda_{j}$ & The belief in the sensitivity to counterparts & {$[0,+\infty)$} \\
$\mathrm{w}_{\mathrm{ij}}$ & The reward of $\mathrm{i}$ of the cooperative action given by the neighbor node $\mathrm{j}$ & {$[0,+\infty)$} \\
$\mathrm{f}$ & The trade facilitation index & {$[0,1]$} \\
$\mathrm{Y}(\mathrm{i})$ & The GDP of the node country $\mathrm{i}$ & $\backslash$ \\
$\mathrm{r}$ & The tariff reduction rate & {$[0,1]$} \\
$\mathrm{Q}(\mathrm{i}, \mathrm{j})$ & The trade volume between node $\mathrm{i}$ and node $\mathrm{j}$ & $\backslash$ \\
\hline
\end{tabular}

\subsection{Model Analysis}

Based on the above assumptions, the total utility value of the node countries at time $t$ is as follows:

$$
U_{i t}\left(s_{i t}, s_{j t}\right)=\sum_{j \in N B R} \sum_{s_{i}} \pi_{i}\left(s_{i t}, s_{j t}\right) P\left(s_{i}\right)+\sum_{j \in N B R, s_{i}=1} w_{i j}+f Y(i)+r \sum_{s_{i}=1} Q(i, j),
$$


Introducing the asymmetrical QRE model:

$$
\begin{gathered}
P\left(s_{i}\right)=\frac{\exp \left[\lambda_{i} \sum_{s_{j}} \widetilde{P}\left(s_{j}\right) u_{i}\left(s_{i}, s_{j}\right)\right]}{\sum_{s_{k}} \exp \left[\lambda_{i} \sum_{s_{-i}} \widetilde{P}\left(s_{j}\right) u_{i}\left(s_{k}, s_{j}\right)\right]} \\
\widetilde{P}\left(s_{j}\right)=\frac{\exp \left[\widetilde{\lambda_{j}} \sum_{s_{-i}} P\left(s_{i}\right) u_{j}\left(s_{i}, s_{j}\right)\right]}{\sum_{s_{-k}} \exp \left[\widetilde{\lambda_{j}} \sum_{s_{i}} P\left(s_{i}\right) u_{j}\left(s_{i}, s_{-k}\right)\right]},
\end{gathered}
$$

Combining with the game payoff matrix in Table 2, the values in the matrix are brought into the formulas (7) and (8), and the formulas (9) and (10) are obtained:

$$
\begin{gathered}
P_{s_{i C}}=\frac{\exp \left[\lambda_{i}\left(P s_{j C} * R+P s_{j D} * S\right]\right.}{\exp \left[\lambda s_{i}\left(P s_{j C} * R+P s_{j D} * S\right]+\exp \left[\lambda_{i}\left(P s_{j c} b+P s_{j D} \ell\right)\right]\right.}, \\
P_{s_{j C}}=\frac{\exp \left[\lambda_{j}\left(P s_{i C} * R+P s_{i D} * S\right]\right.}{\exp \left[\lambda s_{j}\left(P s_{i C} * R+P s_{i D} * S\right]+\exp \left[\lambda_{j}\left(P s_{i C} b+P s_{i D} e\right)\right]\right.}, \\
P_{S_{i C}}=1-P_{S_{i D}}, \\
P_{S_{j C}}=1-P_{S_{j D}}
\end{gathered}
$$

In the network, countries will adjust their behavior strategies according to the revenue situation. When the cooperation revenue of the node countries is greater than the betrayal revenue, they will adopt the cooperation strategy, otherwise they will adjust to the betrayal strategy. Using $\mathrm{N}$ to represent the total number of nodes, and Nc to represent the number of collaborators. The Formula (7)-(10) is brought to the Formula (4), and the Formula (11) can be obtained:

$$
U_{i t}=\left\{\begin{array}{l}
N_{i t}^{c} R P s_{j t}+\left(N-N_{i t}^{c}\right) S\left(1-P s_{j t}\right)+\sum_{j \in N B R, s_{i}=1} w_{i j}+f Y(i)+r \sum_{s_{i}=1} Q(i, j), s_{i}^{t}=1 \\
N_{i t}^{c} T P s_{j t}+\left(N-N_{i t}^{c}\right) P\left(1-P s_{j t}\right), s_{i}^{t}=0
\end{array},\right.
$$

The equilibrium condition for node i to select the cooperation strategy is to satisfy: the benefit of cooperation $\geq$ the benefit of defection, as is shown in Formulas (12) and (13):

$$
\begin{gathered}
N_{i t}^{c} R P s_{j t}+\left(N-N_{i t}^{c}\right) S\left(1-P s_{j t}\right)+\sum_{j \in N B R, s_{i}=1} w_{i j}+f Y(i)+r \sum_{s_{i}=1} Q(i, j) \geq N_{i t}^{c} T P s_{j t}+\left(N-N_{i t}^{c}\right) P\left(1-P s_{j t}\right), \\
\sum_{j \in N B R, s_{i}=1} w_{i j}+f Y(i)+r \sum_{s_{i}=1} Q(i, j)+N_{i t}^{c} S P_{j t}-\left(N-N_{i t}^{c}\right)(P-S)\left(1-P s_{j t}\right) \geq 0,
\end{gathered}
$$

It can be seen from Formula (13) that the choice of strategy made by each node country of the Belt and Road network in a certain round of game is directly related to the reward for cooperation by neighbor nodes, the trade facilitation index, the tariff rate reduction rate, the return of strategies about cooperation and defection, and the probability value of neighbor nodes choosing cooperation. In addition, the probability of neighbor nodes choosing cooperation is directly related to the asymmetry of payoff sensitivity.

\section{Analysis of Simulation Results}

Based on the above model, we analyzed the influence of various factors on "The Belt and Road" economic and trade network through Matlab simulation. The simulation process is shown in Figure 2 and the basic algorithm code is shown in Appendix A. 


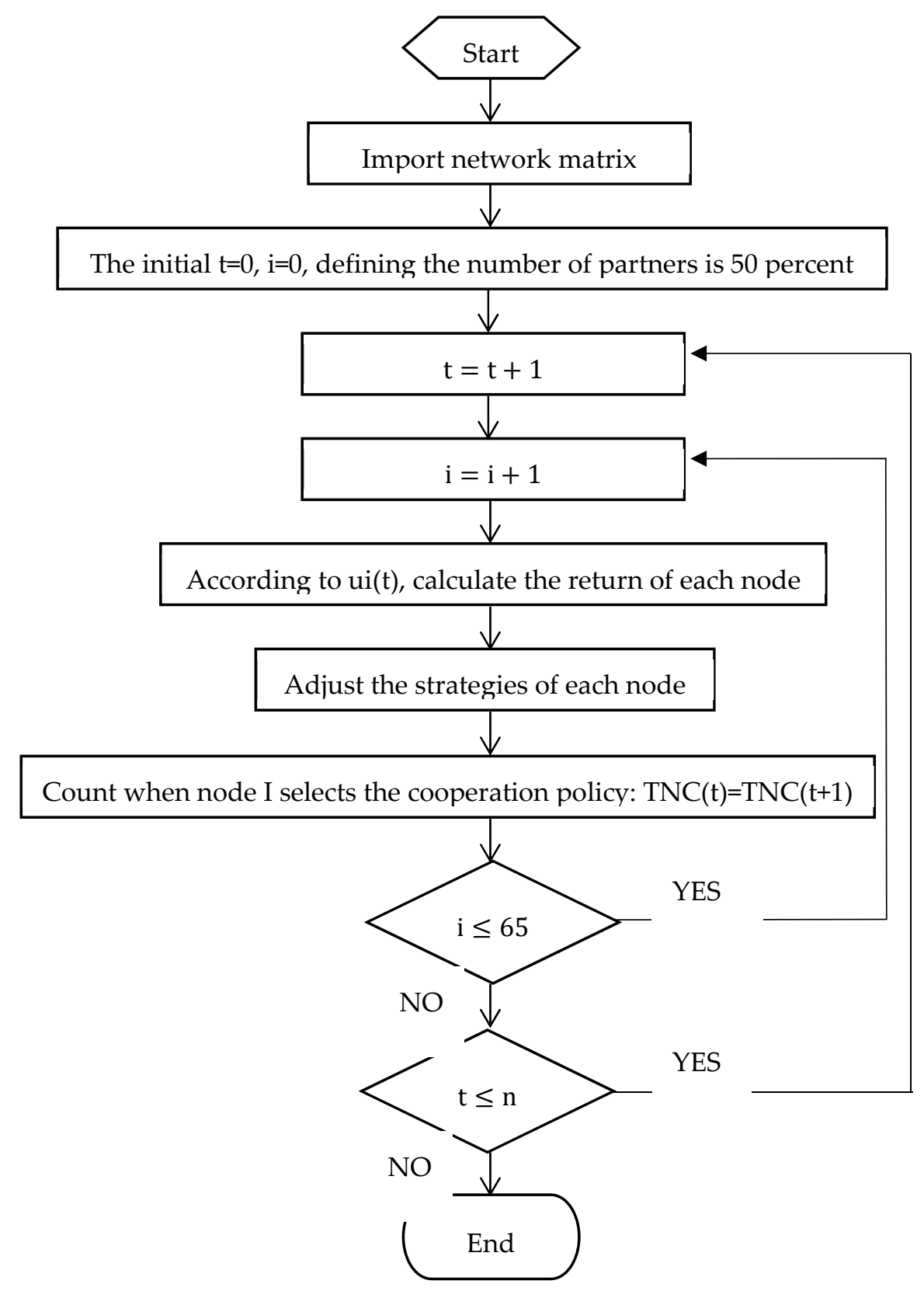

Figure 2. Network game simulation flow chart.

According to the four conditions of value selection in various situations of social dilemma of hypothesis (2), we set $R=5, S=-2, T=6, P=3$ to simplify the model. This simplification did not make substantial changes to our final test results. Considering the range of $\lambda_{i}, \lambda_{j}$, and w, we adopted a value-taking strategy from a small to a large diffusion to test their influence on the cooperative game. At the same time, considering that the setting of the initial value should reflect its influence in the game process, that is, zero value is not desirable, we set $\lambda_{i}=0.2, \lambda_{j}=0.2$ and $\mathrm{w}=0.5$. According to the range of $f$ and $r$, we adopted the strategy of median diffusion to test the influence on the cooperative game and it was very representative of the distribution sequence. Therefore, we set the initial values $f=0.5, r$ $=0.5$. In the initial stage of the game, all countries randomly choose cooperation or betrayal strategies, so $P(0)=0.5$. Such values not only fully consider the realities of "The Belt and Road" economic and trade network, but also make the simulation results show the influence trend and degree of various factors more clearly on the cooperative network. Next, we provided the simulation results in the sub sections. 


\subsection{The Belief in the Sensitivity to Own Payoff $\left(\lambda_{i}\right)$}

When the values of other factors remain unchanged, suppose $\lambda_{i}=0,0.1,0.2,1,10,500$ respectively. The simulation results are shown in Figure 3.

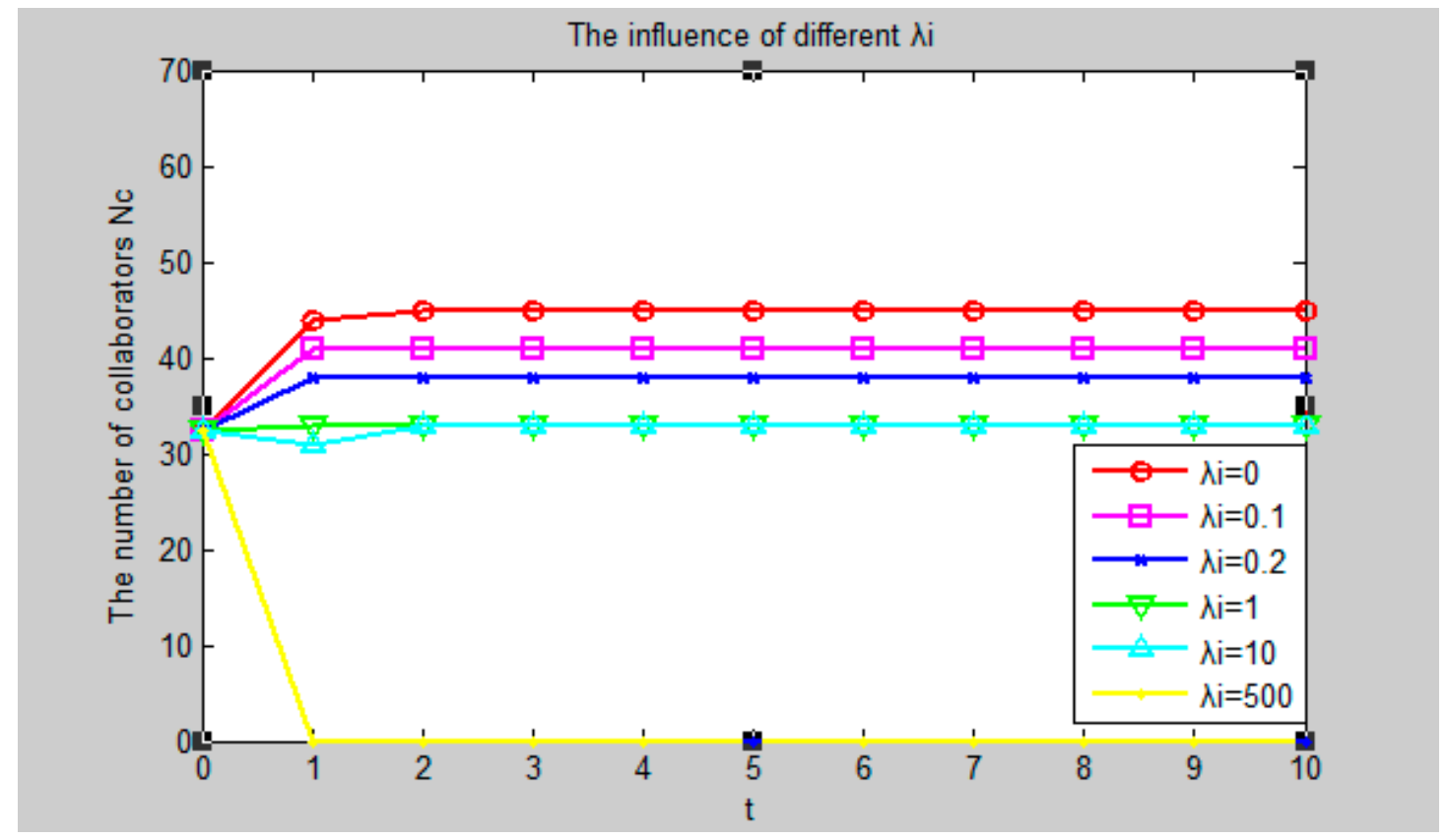

Figure 3. Simulation of the influence of the belief in the sensitivity to own payoff.

As can be seen from Figure 3, suppose the values of other factors remain unchanged: when $\lambda_{i}=0$, the number of cooperators is stable at 45 after three rounds of the game; when $\lambda_{i}=0.1$, the number of cooperators is stable at 41 after two rounds of the game; When $\lambda_{i}=0.2$, the number of cooperators is stable at 38 after two rounds of the game. Finally, when the value is large enough, the number of cooperators is 0 . The results suggest that with the value $\lambda_{i}$ increasing, the stable number of cooperators obtained by the game is decreasing. It can be seen that the growing belief in the sensitivity of countries to their own payments will enable more countries to choose betrayal strategies in "The Belt and Road" economic and trade network, which suggests that the belief in the sensitivity to own payoff is negatively correlated with the equilibrium number of collaborators in the network.

\subsection{The Belief in the Sensitivity to Counterparts $\left(\lambda_{j}\right)$}

When the values of other factors remain unchanged, suppose $\lambda_{j}=0,0.2,1,10,500$ respectively. The simulation results are shown in Figure 4.

As can be seen from Figure 4, suppose the values of other factors remain unchanged: when $\lambda_{j}=0$, the number of cooperators is stable at 40 after three rounds of the game; when $\lambda_{j}=0.2$, the number of cooperators is stable at 38 after one round of the game; when $=1$, the number of cooperators is stable at 36 after two rounds of the game. Finally, when the value is large enough, the number of cooperators is 0 . With the value increasing, the stable number of cooperators obtained by the game is decreasing. It can be seen that the increasing belief in the sensitivity of countries to other countries will make more countries choose betrayal strategies in "The Belt and Road" economic and trade network, which also suggests that the belief in the sensitivity to counterparts is negatively correlated with the equilibrium number of collaborators in the network. 


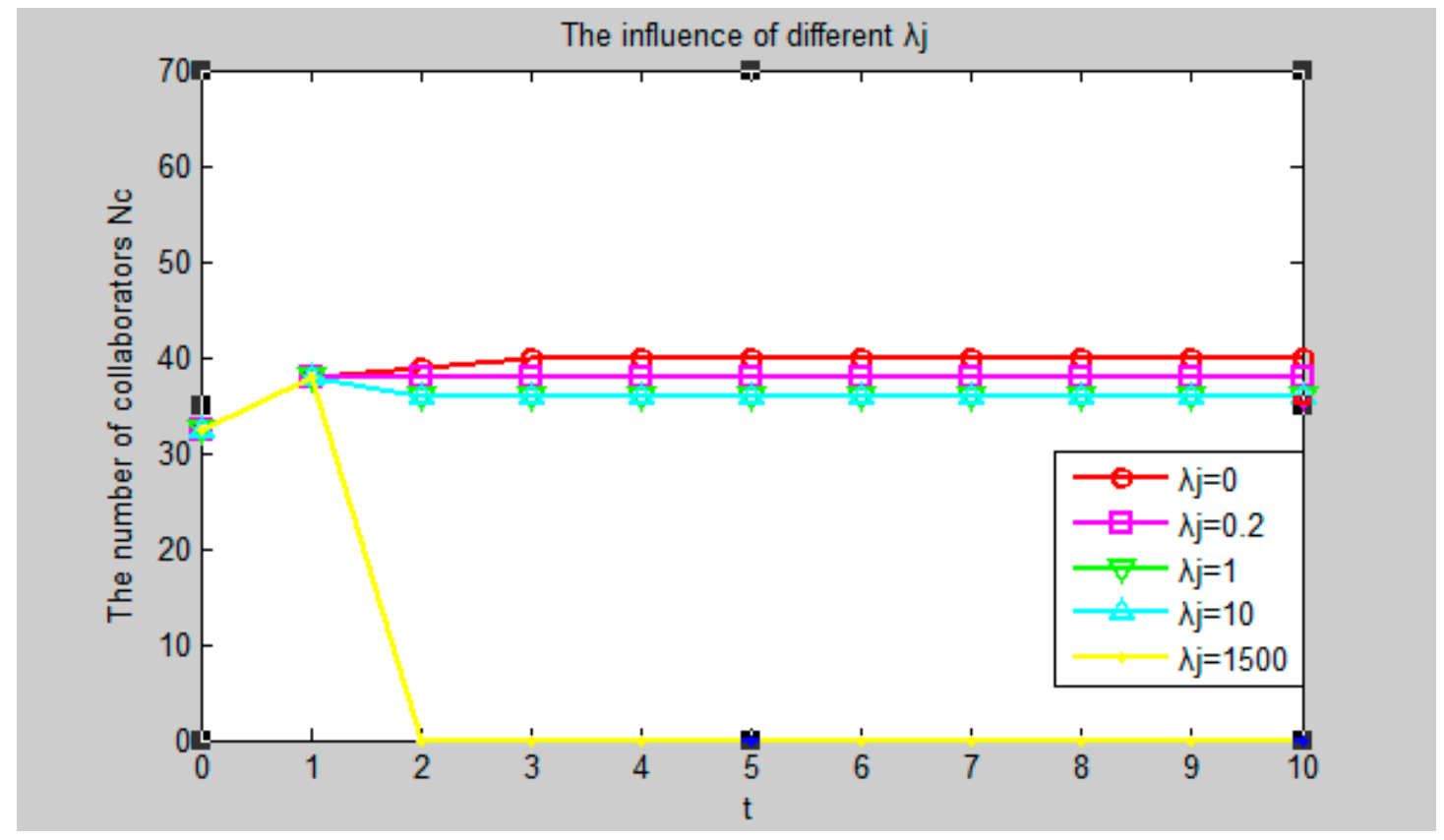

Figure 4. Simulation of the influence of the belief in the sensitivity to counterparts.

\subsection{The Reward for Cooperation by Neighbor Nodes (w)}

When the values of other factors remain unchanged, suppose $\mathrm{w}=0,0.5,1,2,3,5$ respectively. The simulation results are shown in Figure 5.

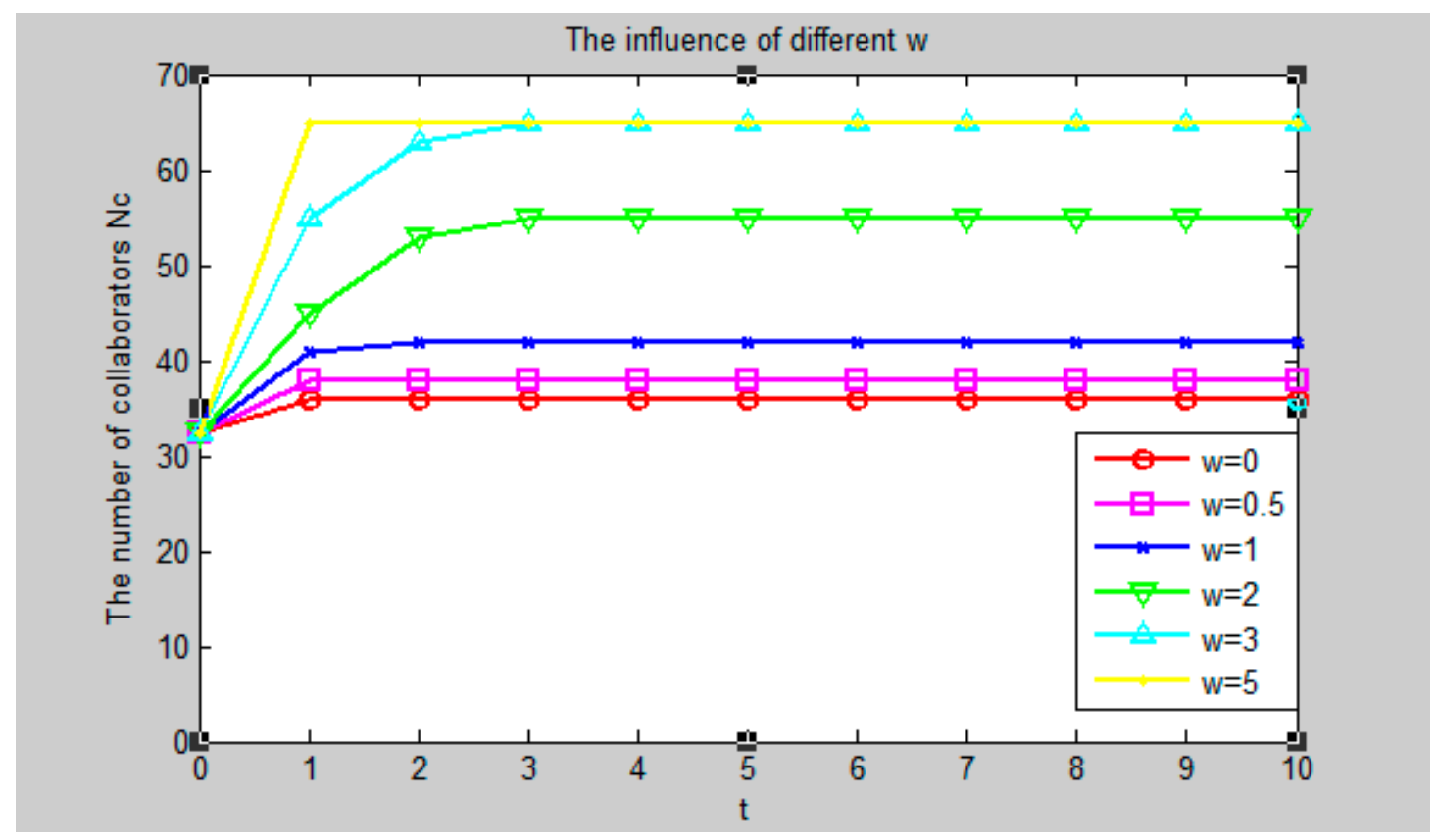

Figure 5. Simulation of the influence of the reward for cooperation by neighbor nodes.

As can be seen from Figure 5, suppose the values of other factors remain unchanged: when $\mathrm{w}=0$, the number of cooperators is stable at 36 after one round of the game; when $\mathrm{w}=0.5$, the number of cooperators is stable at 38 after one round of the game. With the value increasing, the stable number of cooperators obtained by the game is increasing. When $\mathrm{w}=3$, all countries chose cooperation strategy after three rounds of the game. This shows that the rewards for cooperation by neighbor nodes in "The Belt and Road" economic and trade network are positively correlated with the equilibrium number of 
collaborators. In addition, we also notice that when the value of $w$ increased from 3 to 5 , the process of obtaining the equilibrium number of collaborators decreased from three rounds to one round. This further illustrates the role of neighborhood rewards in "The Belt and Road" economic and trade network in promoting cooperative behavior.

\subsection{The Trade Facilitation Index ( $f$ )}

When the values of other factors remain unchanged, suppose $f=0.5,0.2,0.8,0,1$ respectively. The simulation results are shown in Figure 6.

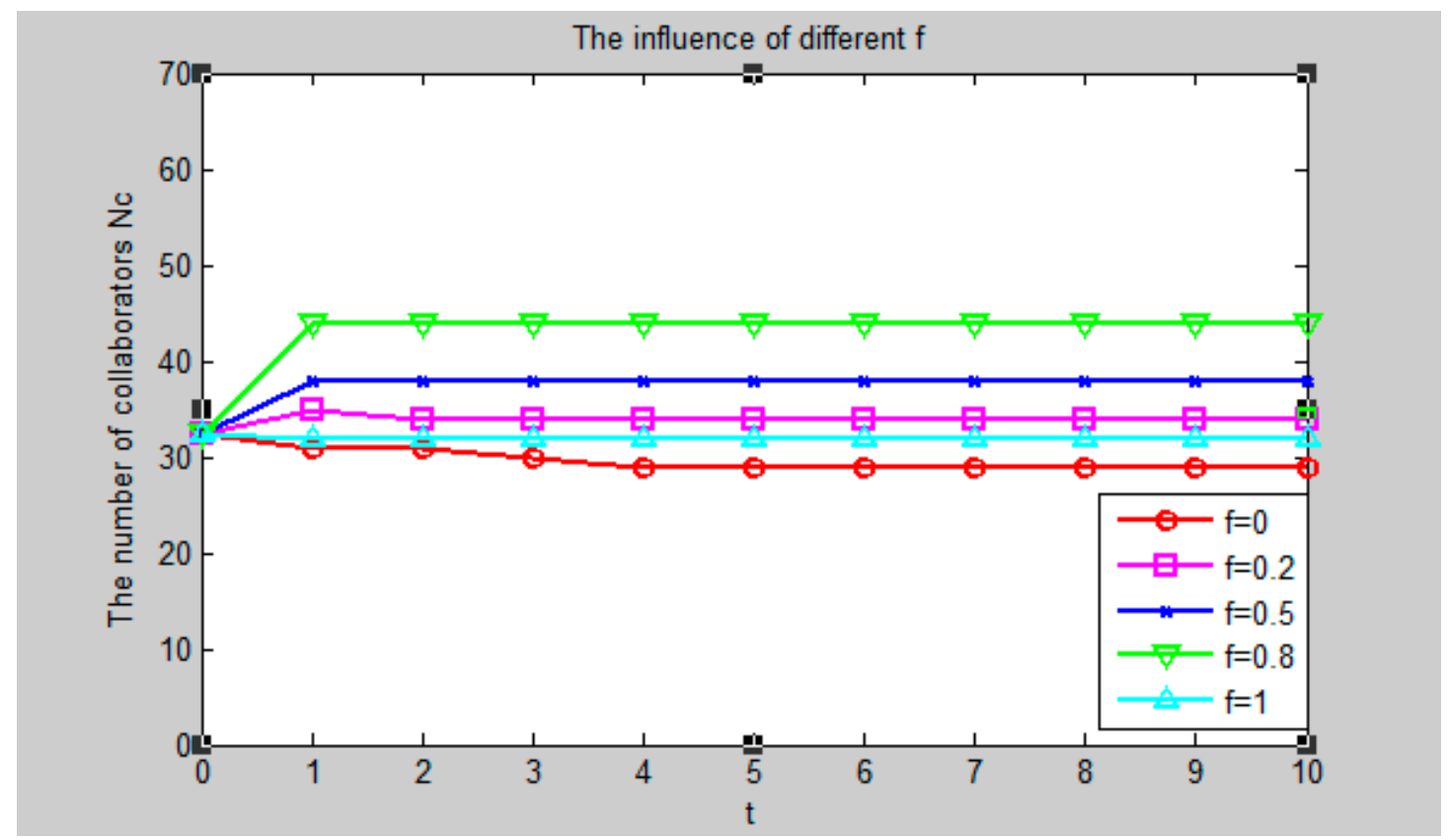

Figure 6. Simulation of the influence of the trade facilitation index.

As can be seen from Figure 6, suppose the values of other factors remain unchanged: when $\mathrm{f}=$ 0 , the number of cooperators is stable at 29 after four rounds of the game; when $f=0.2$, the number of cooperators is stable at 34 after two rounds of the game; when $\mathrm{f}=1$, the number of cooperators is stable at 48 after two rounds of the game. With the value increasing, the stable number of cooperators obtained the game increases. This shows that the trade facilitation index is positively correlated with the equilibrium number of collaborators in "The Belt and Road" economic and trade network. In addition, we also note that the increase of the equilibrium number of collaborators caused by the value from 0.5 to 0.8 is greater than that from 0.2 to 0.5 , which indicates that the influence of trade facilitation index on the equilibrium number of collaborators varies in different ranges.

\subsection{The Reduction Rate of Tariff ( $r$ )}

When the values of other factors remain unchanged, suppose $r=0.5,0.2,0.8,0.1,1,0$ respectively. The simulation results are shown in Figure 7.

As can be seen from Figure 7, suppose the values of other factors remain unchanged, when $r=$ 0 , the number of cooperators is stable at 11 after two rounds of the game; when $r=0.5$, the number of cooperators is stable at 38 after one round of the game; when $r=1$, the number of cooperators is stable at 55 after two rounds of the game. With the value increasing, the stable number of cooperators obtained by the game increases. This shows that the reduction rate of tariffs is positively correlated with the equilibrium number of collaborators in "The Belt and Road" economic and trade network. 


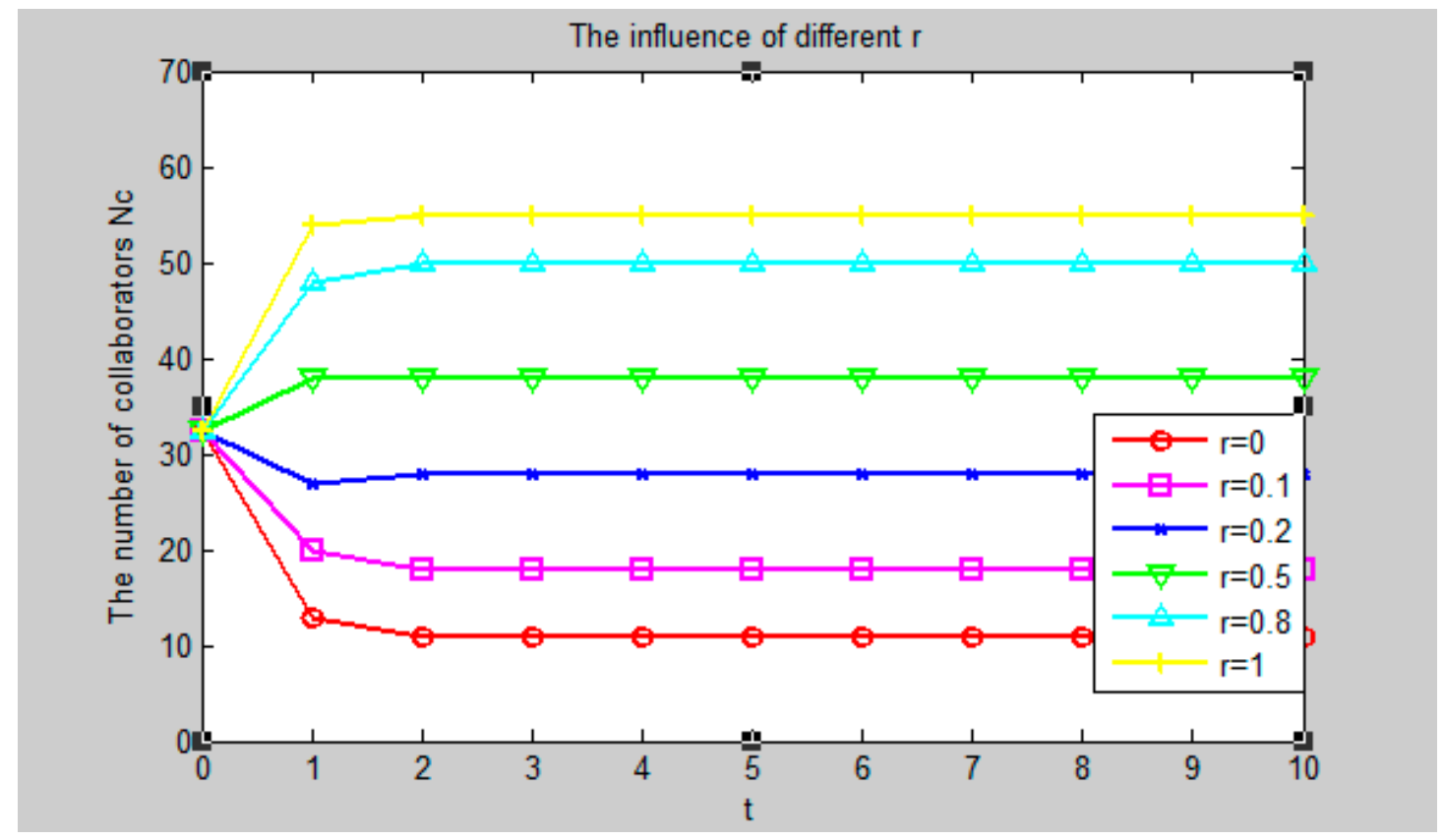

Figure 7. Simulation of the influence of the tariff rate reduction rate.

\section{Discussion and Conclusion}

\subsection{Discussion}

Our paper makes significant contributions to both theory and practice. From the theoretical perspective, our paper maybe the first one to apply the asymmetric Quantal Response Equilibria (QRE) network game model to the belt and road initiative. We explored the influencing factors of the belief in the sensitivity to own payoff and counterparts, the reward for cooperation by neighbor nodes, the trade facilitation index, and the reduction rate of tariffs.

Practically, some new phenomena were discovered. The first is that changes in subjective factors do not necessarily change the strategic choices of all countries in the trade network. Therefore, in the recent issue of the Sino-US trade conflicts, China's optimal strategy is to follow the objective laws of international economy and continue to promote economic and trade cooperation of the Belt and Road. The second is that different trade links already existing in reality have different effects on the choice of cooperation strategies. For countries with close trade links in reality, betrayal will result in greater loss of benefits. Therefore, in "The Belt and Road" trade network, cooperative behavior is a virtuous promotion strategy cycle. The third is that there is always a collaborator in the trade network, no matter how the objective condition variable changes, so cooperation is an endogenous strategy. In addition, the simulation results verify some common sense conclusions, such as the degree of trade facilitation and tariff reduction, which can promote trade cooperation.

According to research conclusions, the strategy of promoting the development of "The Belt and Road" economic and trade network includes the following. First, countries should maintain the flexibility of cooperation strategies. Countries with a different value of belief in sensitivity should be treated separately. They should moderately reduce the value of belief in sensitivity to other countries, which will promote other countries in the network to adopt cooperation strategies with a higher probability. Second, joint countries should increase preferential policies for economic and trade cooperation of the countries of "The Belt and Road", and the equilibrium number of collaborators in the network will increase, which will bring them more benefits. Third, the countries in the network should take full account of their own national conditions and the influence of different factors on the equilibrium number of collaborators, and adopt the best combination of strategies to achieve higher cooperation returns at lower input costs. 


\subsection{Conclusions}

"The Belt and Road" has been a hot topic in the field of politics and economics in recent years. Previous studies on cooperation mostly used qualitative reasoning [10] and quantitative test methods [19], but research results of the complex network game are few. The complex network analysis method incorporates many national subjects into an overall research framework, which is conducive to a better study of the impact of a country's strategic changes on all other countries within the framework. At the same time, it also ignores the influence of asymmetric cognition on "The Belt and Road" economic and trade cooperation in the national decision-making process. Previous studies have examined the impact of objective factors such as tariffs and cultural distance [19] on trade cooperation, but it cannot be ignored that asymmetric subjective decision-making between countries also plays an important role in the process of the cooperative game.

Therefore, based on the construction of "The Belt and Road" economic and trade network, this paper introduced the asymmetric QRE model to set up a complex network game model of "The Belt and Road" economic and trade cooperation. According to the simulation results of the game model, the following conclusions were drawn:

(1) The sensitivity of own payoff and the sensitivity of his counterparts has little influence on the stable number of cooperators in "The Belt and Road" economic and trade network within a limited range of value. This may be the role played by the increasingly rational and mature decision-making process in various countries. At the same time, it means that subjective factors only have an impact on cooperation between countries under some specific conditions. Therefore, when considering promoting the development of an overall trade network, countries should not put subjective factors at the top of their worries.

(2) The rewards of neighbor have a significant impact on the cooperation of "The Belt and Road". Because the neighboring countries in the network are the countries that have close trade relations with each other in reality, this shows that the change of a country's cooperation strategy will first affect those countries which have close trade ties with it. Therefore, countries should first actively communicate with existing trading partners and pursue a higher-level cooperation on the basis of maintaining the existing stable trade relations. At the same time, this also means that the trade network structure has a great influence on the cooperation of "The Belt and Road". Therefore, countries should also strive to improve their position in the trade network in order to obtain more opportunities for trade cooperation.

(3) The level of trade facilitation measures other than the neighbor's rewards is beneficial to the cooperative behavior of "The Belt and Road". The extensive construction of infrastructure such as roads, railways and the Internet will greatly enhance the level of trade facilitation of the entire network, and will further promote the emergence and development of trade cooperation among countries in the network. Therefore, countries along "The Belt and Road" must attach importance to infrastructure construction and attract more cooperation by improving their trade facilitation level, thereby improving their trade status and promoting trade prosperity.

(4) Tariff relief has a significant effect on the cooperative behavior in "The Belt and Road" network. As a traditional trade protection measure, high-level tariffs have become the most frequently adopted trade protection policy in today's anti-globalization tide. However, it has been proved that only low-level tariff and trade liberalization can promote the emergence of trade cooperation between countries, thereby promoting the development and prosperity of the world's economies. Compared with measures of trade protection with high tariffs, countries should maintain an open and inclusive attitude and actively carry out trade cooperation and exchanges with other countries in order to achieve healthy and sustainable development of their trade.

(5) The cooperative behavior in "The Belt and Road" network is the result of the combined effects of many factors. We set a reasonable initial value in the statistical sense, so we obtained a more obvious trend of simulation results. However, in reality, the effect of cooperation will be 
affected by many other factors, but the trend of the impact of the factors we tested on the results was determined.

(6) Our research has some limitations. First, although the influence of the asymmetry of cognition on the equilibrium of the network game was taken into account, the assumption that countries are homogeneous and rational is still too idealistic, which is different from the reality of the countries of "The Belt and Road". Second, the study assumes that the trade network structure is static, but the real trade network is dynamic, and changes in the network structure will influence policy choices. In a future study, we will relax the assumptions, take into account the size of the countries, the social and cultural differences, and other factors, while the weighted network will be used to enhance the reality of the game results.

Author Contributions: Conceptualization, C.Z. and Y.G.; Methodology and Software, Y.W.; Validation, T.Z.; Funding Acquisition, Q.H. All authors contributed to the writing, and have read and approved the final manuscript.

Funding: This research was funded by the National Social Science Fund of China, grant number 16BJY068.

Conflicts of Interest: The authors declare no conflict of interest.

\section{Appendix A}

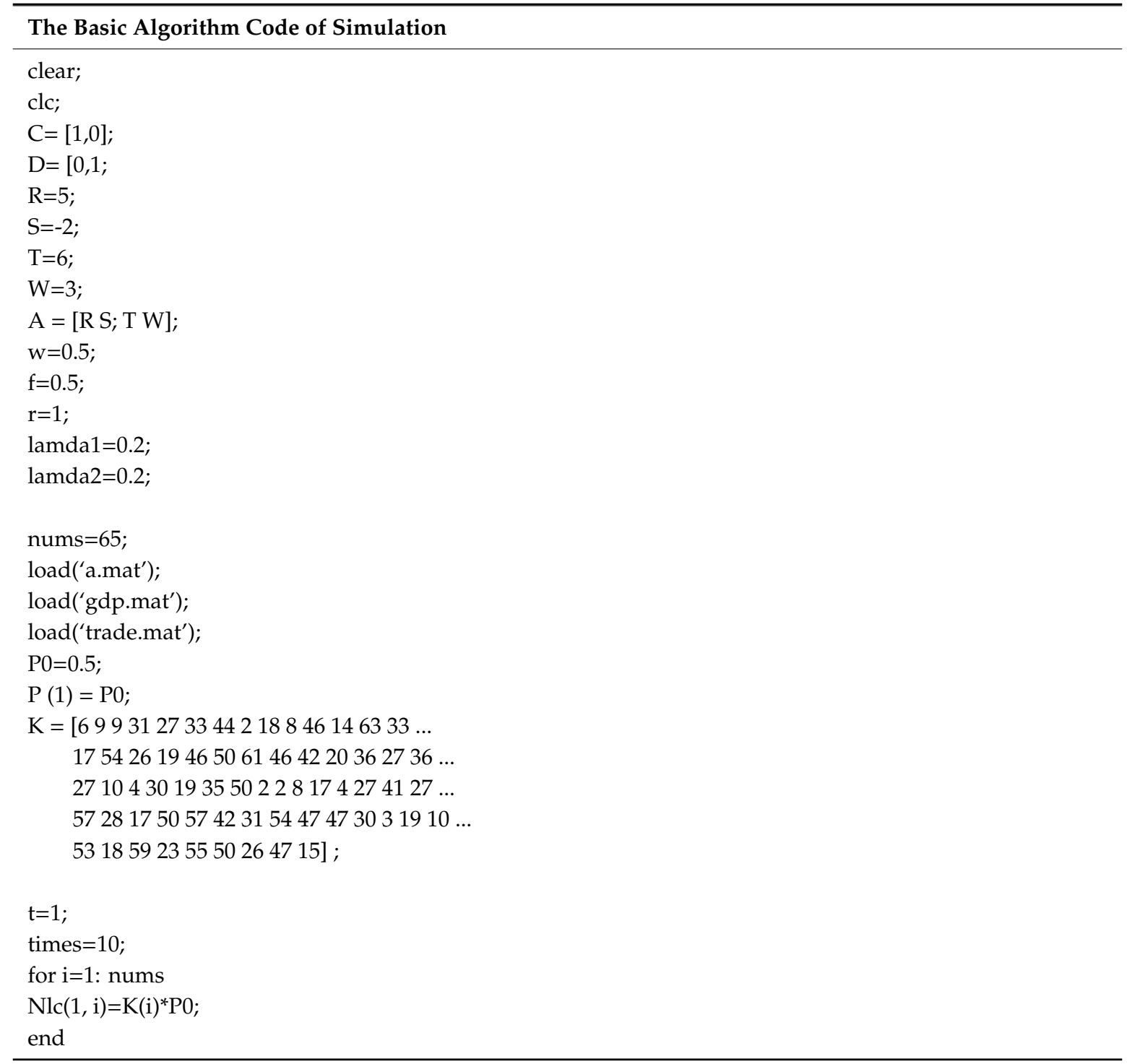




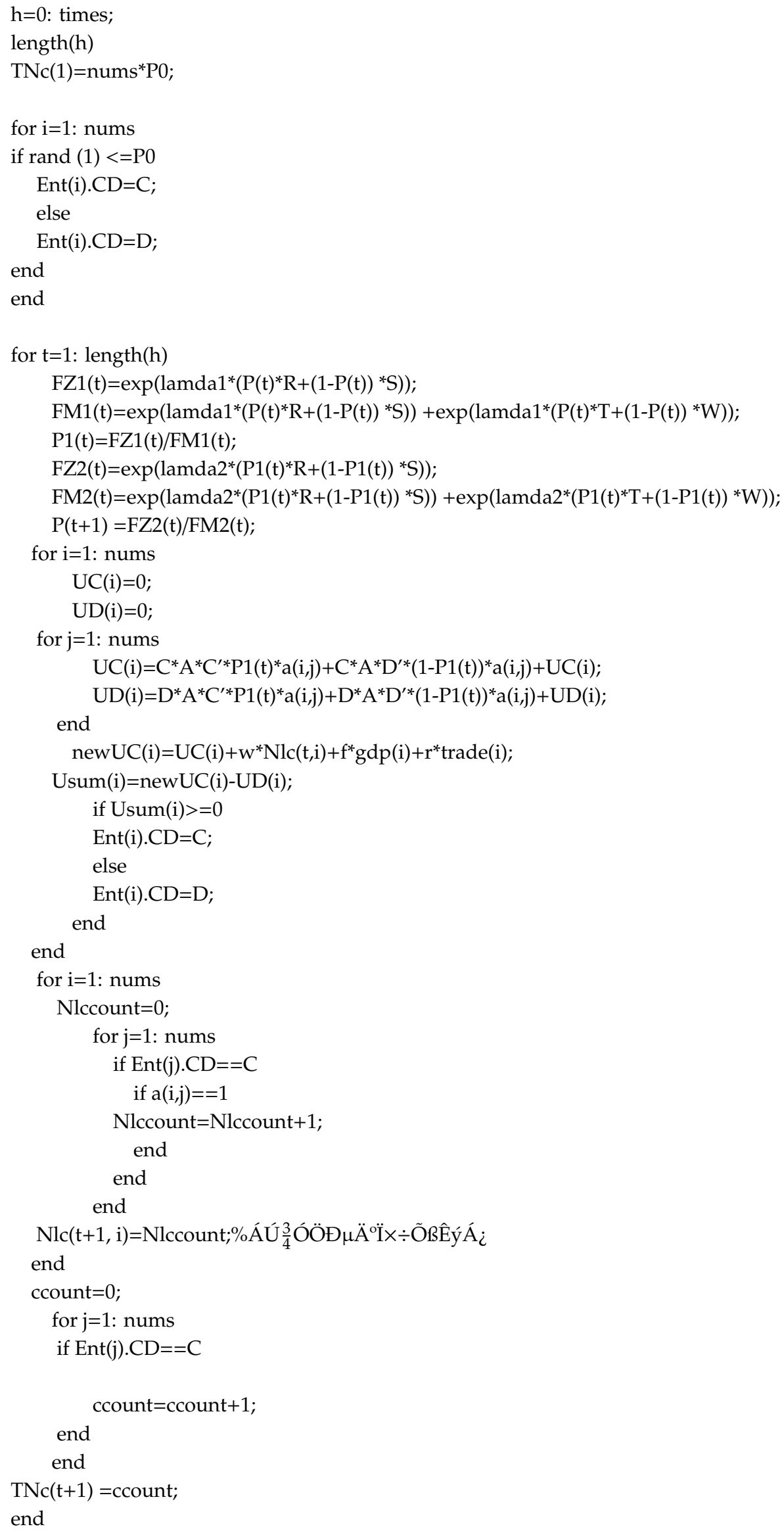




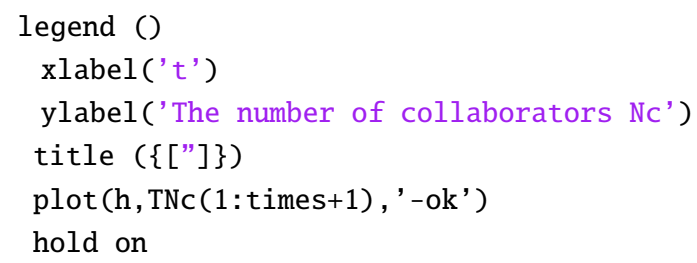

\section{References}

1. The Belt and Road Initiative Progress, Contributions and Prospects. Available online: https://eng.yidaiyilu. gov.cn/zchj/qwfb/86739.htm (accessed on 12 May 2019).

2. The "New Silk Road" Initiative: China's Marshall Plan? Available online: http://www.ciis.org.cn/english/ 2015-06/11/content_7982914.htm (accessed on 12 May 2019).

3. "One Belt One Road": China at the Centre of the Global Geopolitics and Geo-economics? Available online: http://www.southasiaanalysis.org/node/1672 (accessed on 12 May 2019).

4. China Bypasses American 'New Silk Road' with Two if Its Own. Available online: https://www. washingtonpost.com/world/asia_pacific/china-bypasses-american-new-silk-road-with-two-if-its-own/ 2013/10/14/49f9f60c-3284-11e3-ad00-ec4c6b31cbed_story.html?noredirect=on\&utm_term=.612382875a54 (accessed on 12 May 2019).

5. Tiezzi, S. The maritime silk road vs. the string of pearls. Diplomat 2014, 13, 104.

6. Tuo, C. Global Governance and State Governance: Two Strategic Considerations in Contemporary China. Soc. Sci. China 2016, 37, 138-151. [CrossRef]

7. Ling, S.L. The Strategy of the Belt and Road Initiatives and the Reshaping of the Peripheral Geopolitics. J. Int. Relat. 2016, 1, 79-91. (In Chinese)

8. Liu, W.; Dunford, M. Inclusive globalization: Unpacking China's belt and road initiative. Area Dev. Policy 2016, 1, 323-340. [CrossRef]

9. Guo, X. A Study on the International Tourism of Jiangxi Province under the Guidance of One Belt, One Road Strategy. Econ. Soc. Chang. 2016, 3, 221-230. [CrossRef]

10. Andornino, G.B. The Belt and Road Initiative in China's Emerging Grand Strategy of Connective Leadership. China World Econ. 2017, 25, 4-22. [CrossRef]

11. Kenderdine, T. Death of the East Asian Goose and the Rise of China's Geoindustrial Policy. J. Chin. Polit. Sci. 2018, 23, 437-453. [CrossRef]

12. Yu, Y.; Darko, A.; Chan, A.P.; Chen, C.; Bao, F. Evaluation and Ranking of Risk Factors in Transnational Public-Private Partnerships Projects: Case Study Based on the Intuitionistic Fuzzy Analytic Hierarchy Process. J. Infrastruct. Syst. 2018, 24, 04018028. [CrossRef]

13. Fung, K.C.; Aminian, N.; Fu, X.; Kornhohen, I. Internationalization of the use of Chinese currency: Perspectives from the New and the Ancient Silk Roads. J. Chin. Econ. Bus. Stud. 2018, 16, 1-16. [CrossRef]

14. Li, K.X.; Jin, M.; Qi, G.; Shi, W.; Ng, A.K. Logistics as a driving force for development under the Belt and Road Initiative-the Chinese model for developing countries. Transp. Rev. 2018, 38, 457-478. [CrossRef]

15. Chen, C.C.; Chen, C.W.; Tung, Y.C. Exploring the consumer behavior of intention to purchase green products in belt and road countries: An empirical analysis. Sustainability 2018, 10, 854. [CrossRef]

16. Lin, M. India's recognition of "the Belt and Road" and China's policy options. World Econ. Polit. 2015, 5, 42-57. (In Chinese)

17. Yao, R.; Bai, H.; Xu, H. Where should China's thermal power industry prioritize its B\&R investment? A study based on an environmental site selection analysis. J. Clean. Prod. 2019, 215, 669-679.

18. Xu, H.; Sun, T.; Cheng, L. Trade Patterns and Influence Factors of High-end Manufacturing on the Belt and Road. Financ. Trade Econ. 2015, 12, 74-88. (In Chinese)

19. Fu, X.M.; Chen, H.X.; Xue, Z.K. Construction of the belt and road trade cooperation network from the multi-distances perspective. Sustainability 2018, 10, 1439. [CrossRef]

20. McKelvey, R.D.; Palfrey, T.R. Quantal response equilibria for normal form games. Games Econ. Behav. 1995, 10, 6-38. [CrossRef]

21. Friston, K.; Schwartenbeck, P.; FitzGerald, T.; Moutoussis, M.; Behrens, T.; Dolan, R.J. The anatomy of choice: Dopamine and decision-making. Philos. Trans. R. Soc. B Biol. Sci. 2014, 369, 20130481. [CrossRef] 
22. Lim, N.; Ho, T.H. Designing price contracts for boundedly rational customers: Does the number of blocks matter? Mark. Sci. 2007, 26, 312-326. [CrossRef]

23. Ho, T.H.; Zhang, J. Designing pricing contracts for boundedly rational customers: Does the framing of the fixed fee matter? Manag. Sci. 2008, 54, 686-700. [CrossRef]

24. Guarnaschelli, S.; McKelvey, R.D.; Palfrey, T.R. An experimental study of jury decision rules. Am. Polit. Sci. Rev. 2000, 94, 407-423. [CrossRef]

25. Levine, D.K.; Palfrey, T.R. The paradox of voter participation? A laboratory study. Am. Polit. Sci. Rev. 2007, 101, 143-158. [CrossRef]

26. Choi, S.; Gale, D.; Kariv, S. Sequential equilibrium in monotone games: A theory-based analysis of experimental data. J. Econ. Theory 2008, 143, 302-330. [CrossRef]

27. Tumennasan, N. To err is human: Implementation in quantal response equilibria. Games Econ. Behav. 2013, 77, 138-152. [CrossRef]

28. Golman, R. Quantal response equilibria with heterogeneous agents. J. Econ. Theory 2011, 146, $2013-2028$. [CrossRef]

29. Goeree, J.K.; Holt, C.A.; Palfrey, T.R. Quantal response equilibrium and overbidding in private-value auctions. J. Econ. Theory 2002, 104, 247-272. [CrossRef]

30. Neri, C. Quantal response equilibrium in a double auction. Econ. Theory Bull. 2015, 3, 79-90. [CrossRef]

31. Bandyopadhyay, S.; Coughlin, C.C.; Wall, H.J. Ethnic networks and US exports. Rev. Int. Econ. 2008, 16, 199-213. [CrossRef]

32. Reimer, J.J.; Zhang, X. An economic model of search and matching in international trade. Rev. Int. Econ. 2018, 26, 784-800. [CrossRef]

33. Schoenenberger, L.; Tanase, R. Controlling complex policy problems: A multimethodological approach using system dynamics and network controllability. J. Simul. 2018, 12, 162-170. [CrossRef]

34. Ribino, P.; Cossentino, M.; Lodato, C.; Lopes, S. Agent-based simulation study for improving logistic warehouse performance. J. Simul. 2018, 12, 23-41. [CrossRef]

35. Junior, W.L.; Rosário, D.; Cerqueira, E.; Villas, L.A.; Gerla, M. A Game Theory Approach for Platoon-Based Driving for Multimedia Transmission in VANETs. Wirel. Commun. Mob. Comput. 2018, 2018. [CrossRef]

36. Pellan, M.I.; Wong, M.H. Trade facilitation in ASEAN and ASEAN+ 1 FTAS: An analysis of provisions and progress. J. World Trade 2013, 47, 243.

37. Gowa, J.; Hicks, R. “Big” Treaties, Small Effects: The RTAA Agreements. World Polit. 2018, 70, $165-193$. [CrossRef]

38. Promote the Construction of the Silk Road Economic Belt and the Vision and Action of the Maritime Silk Road in 21st Century. Available online: http://www.mofcom.gov.cn/article/i/jyjl/k/201504/20150400930662.shtml (accessed on 12 May 2019).

39. UNCTDs. Available online: http://unctad.org/en/Pages/statistics.aspx (accessed on 4 May 2019).

40. Anderson, S.P.; Goeree, J.K.; Holt, C.A. The logit equilibrium: A perspective on intuitive behavioral anomalies. South. Econ. J. 2002, 21-47. [CrossRef]

41. Hofbauer, J.; Sigmund, K. Evolutionary game dynamics. Bull. Am. Math. Soc. 2003, 40, 479-519. [CrossRef]

42. Sankaranarayanan, K.; Delgado, C.; Van Ackere, A.; Larsen, E.R. The micro-dynamics of queuing: Understanding the formation of queues. J. Simul. 2014, 8, 304-313. [CrossRef]

43. Facchinei, F.; Kanzow, C. Generalized Nash equilibrium problems. 4OR 2007, 5, 173-210. [CrossRef]

44. Choi, S.; Gale, D.; Kariv, S. Social learning in networks: A quantal response equilibrium analysis of experimental data. Rev. Econ. Des. 2012, 16, 135-157. [CrossRef]

(C) 2019 by the authors. Licensee MDPI, Basel, Switzerland. This article is an open access article distributed under the terms and conditions of the Creative Commons Attribution (CC BY) license (http://creativecommons.org/licenses/by/4.0/). 